\title{
How do patients with HIV perceive their general practitioners?
}

Michael M Kochen, Joerg C Hasford, Hans Jäger, Stephan Zippel, Manfred L'age, Carla Rosendahl, Hermann S Füeßl, Dieter Eichenlaub

Abstract

Objective-To study the perceptions of patients with HIV of their general practitioners in terms of knowledge, abilities, confidence, and satisfaction.

Design-Questionnaire survey of inpatients, outpatients, and members of a self help group.

Setting-Two city hospitals, three outpatient clinics, and one AIDS self help group in Munich and Berlin, Germany

Subjects-All 402 patients available between 1 September 1988 and 31 May 1989.

Main outcome measures-General practitioners' attitudes towards the patients' HIV status; patients' experience of treatment rejection; reception in the general practitioner's office; the doctor's perceived knowledge about HIV and AIDS.

Results -394 of 402 patients consented to interview; $87 \%$ were registered with a general practitioner and $91 \%$ of those indicated that the doctor was aware of their HIV diagnosis. The overwhelming majority of patients $(94 \%)$ had a friendly or at least neutral reception in the general practitioner's surgery and only six patients' general practitioner changed his or her behaviour for the worse because of the HIV diagnosis. Two thirds of patients said they would consult first with their primary care doctor for a physical problem, but only $13 \%$ would do so for psychological problems. Over a third of the patients did not routinely inform other doctors or medical staff about their HIV status, but there was no significant correlation between this concealment and ever having been rejected by a doctor $(7 \%)$ or a dentist (12\%).

Conclusion-Most patients expressed a high degree of satisfaction with their general practitioners in terms of confidential issues, attitudes, knowledge, and management.

Therapeutic Studies,

Munich

Joerg C Hasford, MD, head

Schwabing City Hospital, Munich

Hans Jäger, MD, senior registrar, immunodeficiency clinic

Dieter Eichenlaub, MD, head, department of medicine IV

AIDS-Hilfe, Munich Stephan Zippel, MS, psychologist

Department of Medicine II Auguste-Viktoria Hospital, Berlin

Manfred L'age, MD, head

Correspondence to:

Professor Michael M

Kochen, Department of

General Practice, University

of Göttingen, Robert-Koch-

Strasse 40, W-3400

Göttingen, Germany.

BMF 1991;303:1365-8
The attitudes of general practitioners towards HIV infection and AIDS have been investigated, ${ }^{4-6}$ but little is known about affected patients' views of their primary care doctors. ${ }^{7}$ We studied HIV patients' perceptions of their general practitioners in terms of knowledge, abilities, confidence, and satisfaction.

\section{Subjects and methods}

HIV patients were interviewed with an anonymous questionnaire in two hospitals, three outpatient clinics, and one self help group in Munich and West Berlin between 1 September 1988 and 31 May 1989. The survey was conducted outside of general practitioners' surgeries to avoid "environmental" bias. Munich and Berlin are among the four municipal centres with the highest prevalence of HIV in Germany (National AIDS Centre of the Federal Health Authority, personal communication).

A total of 402 patients were approached, 394 of whom gave informed consent and were subsequently interviewed. In all, $82(20 \%)$ of the 402 patients were hospitalised; 128 patients (33\%) accepted the help of a nurse to answer the questionnaire. Not all patients replied to all questions: the number of patients answering individual questions ranged from 301 to 394 . In the case of seven perinatally infected children their mothers answered for them.

Patients were asked for their own and their general practitioner's demographic data, place of HIV testing, general practitioner's knowledge and attitude towards the patient's HIV status, whether treatment had ever been refused, reception in the general practitioner's office, and perceived level of the doctor's knowledge about HIV and AIDS. In a few cases we checked the data given about doctors and found them reliable. To control for patients' answers with respect to being refused treatment by doctors or dentists we asked a subsample of 187 patients whether they had changed their general practitioner (and if so whether this was because of HIV infection).

In Germany, unlike in the United Kingdom, not only general practitioners but also internists and other specialists can open a private practice. Most internists in private practice do exactly the same work as general practitioners. From the obligatory information shown on prescriptions, stationery, or the practice shingle patients can easily recognise if a doctor is a vocationally trained and board certified family practitioner (Allgemeinarzt), a general practitioner without that formal qualification (Praktischer Arzt), or an internist. For the purpose of this study all physicians designated by the patients as their primary care doctors ("house doctors") are called general practitioners whether they were "real" general practitioners, internists, or other specialists.

Absolute and relative frequencies of responses to the questionnaire were tabulated. Pearson $\chi^{2}$ tests were used to investigate associations between variables. As there were no a priori hypotheses the $p$ values given are to be interpreted descriptively.

\section{Results}

DEMOGRAPHY AND HIV STATUS

Tables I and II show demographic data and HIV status of patients. Significantly fewer women 
TABLE I-Demographic data of patients with HIV in two German cities

\begin{tabular}{lc}
\hline & No $(\%)$ replying \\
\hline Sex $(\mathrm{n}=394)$ & \\
Male & $345(88)$ \\
Female & $49(12)$ \\
Age $($ years $)(\mathrm{n}=394)$ & $13(3)$ \\
$\leqslant 14$ & $20(5)$ \\
$15-$ & $258(66)$ \\
$21-$ & $98(25)$ \\
$41-$ & $5(1)$ \\
$>60$ & $149(40)$ \\
Education $(\mathrm{n}=372)$ & $97(26)$ \\
Elementary school & $9(2)$ \\
Secondary school & $2(<1)$ \\
High school & \\
University & $195(51)$ \\
Family contacts $(\mathrm{n}=382)$ & $120(31)$ \\
Good to excellent & $31(8)$ \\
Average & $36(9)$ \\
Bad & \\
Broken off & \\
\hline
\end{tabular}

TABLE II-Data on HIV infection of patients in two German cities

\begin{tabular}{|c|c|}
\hline & No (\%) replying \\
\hline \multicolumn{2}{|l|}{ Risk group $(\mathrm{n}=378)$} \\
\hline Homosexual or bisexual men & $266(70)$ \\
\hline Intravenous drug users & $58(15)$ \\
\hline Haemophilic or received blood transfusion & $27(7)$ \\
\hline Heterosexual transmission & $20(5)$ \\
\hline Perinatally infected children & $7(2)$ \\
\hline \multicolumn{2}{|l|}{ HIV status $\left(\mathrm{CDC}^{\star}\right)(\mathrm{n}=353 ; 308 \mathrm{men}, 45$ women $)$} \\
\hline Asymptomatic infection (CDC II) & $164(47)$ \\
\hline Men & $133(43)$ \\
\hline Women & $31(69)$ \\
\hline $\begin{array}{l}\text { AIDS related complex or lymphadenopathy syndrome } \\
\text { (CDC III) }\end{array}$ & $63(18)$ \\
\hline Men & $54(18)$ \\
\hline Women & $9(20)$ \\
\hline AIDS (CDC IV) & $126(36)$ \\
\hline Men & $121(39)$ \\
\hline Women & $5(11)$ \\
\hline \multicolumn{2}{|l|}{$\begin{array}{l}\text { Hospitalisation associated with } \mathrm{HIV} \text { ( } \mathrm{n}=384 ; 337 \mathrm{men} \text {, } \\
47 \text { women) }\end{array}$} \\
\hline Never & $202(53)$ \\
\hline Men & $170(50)$ \\
\hline Women & $32(69)$ \\
\hline Once & $92(24)$ \\
\hline Men & $82(24)$ \\
\hline Women & $10(21)$ \\
\hline 2-5 Times & $82(21)$ \\
\hline Men & $77(23)$ \\
\hline Women & $5(11)$ \\
\hline$>5$ Times & $8(2)$ \\
\hline Men & $8(2)$ \\
\hline Women & 0 \\
\hline
\end{tabular}

${ }^{\star}$ Centres for Disease Control staging.

TABLE III - Sex, age, and risk group compared with national AIDS registry. Figures are percentages

\begin{tabular}{lrr}
\hline & $\begin{array}{c}\text { Study } \\
\text { data }\end{array}$ & $\begin{array}{c}\text { National } \\
\text { data }\end{array}$ \\
\hline Sex & & \\
$\quad$ Male & $87 \cdot 6$ & $90 \cdot 5$ \\
Female & $12 \cdot 4$ & $9 \cdot 5$ \\
Age (years) & $3 \cdot 3$ & $1 \cdot 0$ \\
14 & $5 \cdot 0$ & $0 \cdot 6$ \\
$15-$ & $65 \cdot 5$ & $56 \cdot 7$ \\
$21-$ & $24 \cdot 9$ & $38 \cdot 9$ \\
$41-$ & $1 \cdot 3$ & $2 \cdot 8$ \\
P60 & $70 \cdot 4$ & $69 \cdot 9$ \\
Risk groupt & $15 \cdot 3$ & $13 \cdot 4$ \\
Homosexual or bisexual men & $7 \cdot 1$ & $6 \cdot 7$ \\
Intravenous drug users & $5 \cdot 3$ & $3 \cdot 7$ \\
Haemophilic or received blood transfusion & $1 \cdot 9$ & $0 \cdot 6$ \\
Heterosexual transmission & & \\
Perinatally infected children & & \\
\hline
\end{tabular}

^As of 31 December 1990; fullblown AIDS cases only. +National data includes $6 \%$ unknown risk group.

$(\mathrm{p}<0.0007)$ than men had symptoms, and women were also admitted to hospital less often.

Compared with national epidemiological data of fullblown AIDS cases (table III) our sample included more women patients aged under 40 and more perinatally infected children. Although the severity of infection in our patients ranged from asymptomatic to fullblown disease we chose national data on AIDS rather than on HIV for comparison because laboratory data on HIV infection, being anonymously registered, contain many omissions (sex is unknown in $15 \%$, age in $25 \%$, and risk group in $68 \%$; National AIDS Centre of the Federal Health Authority, personal communication).

The level of education in our group was relatively low: only nine $(2 \%)$ had finished high school and two $(<1 \%)$ patients indicated that they had a university degree, compared with $9 \%$ and $7 \%$ nationally. ${ }^{8}$

GENERAL PRACTITIONERS

Of 389 patients who replied, $339(87 \%)(86 \%$ (295) men and $92 \%$ (44) women) were registered with a general practitioner. Nationälly, $86 \%$ of the population is registered with a general practitioner.

Of the doctors, 291 were mat and 45 were female. कै When asked to estimate their doctor's age none of the $\overrightarrow{0}$ patients indicated that their doctor was younger than 30; 277 estimated an age between 30 and 50;50, between 50 and 60 ; and eight, older than 60 . A total of 156 doctors were family practitioners or general 3 . practitioners (88 with and 68 without vocational training and board certification), 161 were internists, and 12 were specialists in other fields.

\section{CONFIDENTIALITY ISSUES}

General practitioners' surgeries and clinics or $\mathscr{\sigma}$ hospitals seem to be more popular than local public health departments for having HIV antibody assays performed and are most trusted by patients (table IV).

TABLE IV-Patients' rating of confidentiality issues

No (\%) replying

Place of HIV testing $(n=373)$

GP surgery

Clinic or hospital

Public health department

Other

I trust most $(n=367)$

GP

Clinic or hospital

Public health department

Other (non-medical practitioner, friend, family)

GP aware of HIV diagnosis ${ }^{\star}(n=335)$

Yes

No

Reasons given for GP not aware of HIV diagnosis ${ }^{\star}(n=24)$

Too little anonymity
Too little confidence

Others (small town, GP also caring for family, no opportunity to tell)

I regularly inform other doctors or medical staff about

my HIV state $(n=359)$

Always

Sometimes

Never

$133(36)$

$133(36)$
$148(40)$

$52(14)$

$40(11)$

$145(40)$

$175(48$

$1(<1)$
$46(13)$

$306(91)$

$29(9)$

$5(21)$

$7(29)$

$12(50)$

$\star$ Only patients registered with a general practitioner were considered.

Patients both favoured and trusted the clinic or hospital more than they did general practitioners. $\widetilde{N}$ When patients' confidence in general practitioners versus clinics or hospitals was tabulated against their risk groups this picture became even clearer (table V). 0 Children were exclusively cared for by a specialised N university clinic so the unanimous vote of theiro mothers was not surprising.

There was no significant correlation between education or family contact and direction of confidence. $\stackrel{\infty}{+}$ Women were less confident than men in general 0 practitioners $(34 \%(15 / 45) v 41 \%(132 / 322))$ and clinics or hospitals $(37 \%(17 / 45) v 49 \%(157 / 322))$.

General practitioners of most $(91 \%)$ patients were $\overrightarrow{\mathbb{Q}}$ aware of the patients' HIV diagnosis; the reasons giveno by 24 of the 29 patients who did not inform their general practitioner are detailed in table IV. It iso noteworthy that over a third of patients did not routinely inform other doctors or medical staff abouto their HIV status (table IV). This concealment was not significantly correlated to ever having been rejected by a doctor or dentist. 


\begin{tabular}{lrrcc}
\hline & \multicolumn{4}{c}{ Most confidence in: } \\
\cline { 2 - 5 } Risk group & GP & $\begin{array}{c}\text { Clinic or } \\
\text { hospital }\end{array}$ & $\begin{array}{c}\text { Public health } \\
\text { department }\end{array}$ & Others \\
\hline Homosexual or bisexual men & $112(43)$ & $123(47)$ & $1(<1)$ & $27(10)$ \\
Intravenous drug users & $18(34)$ & $23(43)$ & & $12(23)$ \\
Haemophilic or received blood transfusion & $10(40)$ & $13(52)$ & & $2(8)$ \\
Heterosexual & $5(27)$ & $9(47)$ & & $5(7)$ \\
Perinatally infected children & & $7(100)$ & \\
\hline Total $(\mathbf{n}=367)$ & $145(40)$ & $175(48)$ & $1(<1)$ & $46(13)$ \\
\hline
\end{tabular}

GENERAL PRACTITIONERS' SERVICES AND ATTITUDES

Reception of HIV patients in the general practice surgery by the doctor and staff was mostly friendly or neutral, and almost all general practitioners either did not change their behaviour or did it for the better after the patient had been diagnosed as HIV positive (table VII). Refusal to give treatment had been experienced nearly twice as often from dentists as from doctors $(37 / 301 v 24 / 344 ; \mathrm{p}<0.025)$.

GENERAL PRACTITIONERS' KNOWLEDGE AND ABILITIES

Almost two thirds of patients $(60 \% ; 234)$ would go to the general practitioner first when experiencing $\overline{\bar{O}}$ physical problems, but only $13 \%$ (46) would do so in

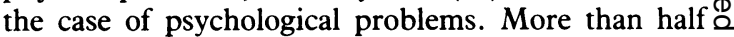
$(56 \% ; 199)$ would first approach friends or self help groups for psychological problems (table VIII). Never- $\overrightarrow{0}$ theless, general practitioners' knowledge of HIV was rated as excellent or good by $68 \%$ (215) of the patients. $\vec{\omega}$

TABLE VIII-Patients' rating of general practitioners' knowledge and $\overline{3}$ abilities

Those patients who changed their general practitioner were significantly more ill than those who did not (table VI; $\mathrm{p}<0.013$ for all differences in HIV status); they were also admitted to hospital more often $(p=0.08)$. Although more of those who had changed general practitioners rated their doctor's knowledge of HIV as excellent $(p=0.04)$, their satisfaction was significantly lower than that of patients who had not changed general practitioners $(p<0.02)$.

TABLE VI-Comparison of patients who did and did not change general practitioner in a subsample of 187 patients

\begin{tabular}{lcc}
\hline- & $\begin{array}{c}\text { No }(\%) \text { of } \\
\text { patients who } \\
\text { changed GP }\end{array}$ & $\begin{array}{c}\text { No }(\%) \text { of } \\
\text { patients who } \\
\text { did not } \\
\text { change GP }\end{array}$ \\
\hline HIV status & $(\mathrm{n}=29)$ & $(\mathrm{n}=130)$ \\
No symptoms & $7(24)$ & $67(52)$ \\
AIDS related complex or lymphadenopathy & & \\
$\quad$ syndrome & $4(14)$ & $19(15)$ \\
AIDS & $18(62)$ & $44(34)$ \\
Hospitalisation associated with HIV & $(\mathrm{n}=33)$ & $(\mathrm{n}=147)$ \\
Never & $12(36)$ & $80(54)$ \\
Once & $8(24)$ & $39(27)$ \\
2-5 times & $11(33)$ & $24(16)$ \\
>5 Times & $2(6)$ & $4(3)$ \\
GP's knowledge of HIV & $(\mathrm{n}=30)$ & $(\mathrm{n}=137)$ \\
Excellent & $13(43)$ & $36(26)$ \\
Good & $11(37)$ & $55(40)$ \\
Average & $1(3)$ & $29(21)$ \\
Moderate & $5(17)$ & $11(8)$ \\
Poor & $0(0)$ & $6(4)$ \\
Satisfaction with GP & $(\mathrm{n}=30)$ & $(\mathrm{n}=142)$ \\
Very high & $13(43)$ & $84(59)$ \\
High & $8(27)$ & $43(30)$ \\
Average & $9(30)$ & $12(8)$ \\
Low & $0(0)$ & $1(1)$ \\
Very low & $0(0)$ & $2(1)$ \\
\hline
\end{tabular}

TABLE VII-Patients' rating of general practitioners' services and attitudes

\begin{tabular}{lc}
\hline & No $(\%)$ replying \\
\hline Reception in surgery by $\mathrm{GP}^{\star}(\mathrm{n}=332)$ & \\
Friendly or neutral & $324(98)$ \\
Reserved & $8(2)$ \\
Negative & \\
Reception in surgery by other staff $(\mathrm{n}=331)$ & $310(94)$ \\
Friendly or neutral & $20(6)$ \\
Reserved & $1(<1)$ \\
Negative & $320(93)$ \\
Treatment ever refused by a doctor $(\mathrm{n}=344)$ & $15(4)$ \\
Never & $8(2)$ \\
Once & $1(<1)$ \\
$2-5$ Times & $26488)$ \\
$>5$ Times & $26(9)$ \\
Treatment ever refused by a dentist $(\mathrm{n}=301)$ & $11(4)$ \\
Never & \\
Once & \\
$2-5$ Times & \\
$>5$ Times & $275(87)$ \\
Any change of GP's behaviour since HIV diagnosis & $36(11)$ \\
known $(\mathrm{n}=317)$ & $6(2)$ \\
No & \\
Yes, for the better & \\
Yes, for the worse &
\end{tabular}

$\star$ Only patients registered with a general practitioner were considered.

No (\%) replying

\begin{tabular}{|c|c|}
\hline \multicolumn{2}{|c|}{ With physical problems I go first to $(n=388)$ : } \\
\hline GP & $234(60)$ \\
\hline Hospital or clinic & $133(34)$ \\
\hline \multicolumn{2}{|l|}{ Public health department } \\
\hline Friends or self help group & $11(3)$ \\
\hline Other (non-medical practitioners, etc) & $10(3)$ \\
\hline \multicolumn{2}{|c|}{ With psychological problems I go first to $(n=353)$ : } \\
\hline GP & $46(13)$ \\
\hline Hospital or clinic & $35(10)$ \\
\hline Public health department & $1(<1)$ \\
\hline Friends or self help group & $199(56)$ \\
\hline Other (partner, family, psychologist) & $72(20)$ \\
\hline \multicolumn{2}{|l|}{ GP's knowledge of $\mathrm{HIV}^{\star}(\mathrm{n}=318)$} \\
\hline Excellent & $108(34)$ \\
\hline Good & $107(34)$ \\
\hline Average & $62(20)$ \\
\hline Moderate & $31(10)$ \\
\hline Poor & $10(3)$ \\
\hline
\end{tabular}

^Only patients registered with a general practitioner were considered.

\section{SATISFACTION}

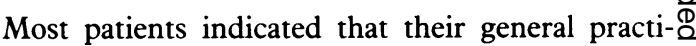
tioner had enough time for them $(83 \% ; 275)$ and that $\overrightarrow{\vec{B}}$ (table IX). Satisfaction was not significantly correlated? with either sex, age, education, family contact, risk우 group, or doctor's specialty (for example, family practitioner or general practitioner, internist). Less than a third of the patients $(26 \% ; 88)$ expressed a desire for a stronger commitment of their general practitioner 3 towards HIV and AIDS.

TABLE IX - Patients' satisfaction with general practitioner

No (\%) replying N

\begin{tabular}{|c|c|}
\hline \multicolumn{2}{|c|}{ Satisfaction with $\mathrm{GP}^{\star}(\mathrm{n}=335)$} \\
\hline Very high & $179(53)$ \\
\hline High & $101(30)$ \\
\hline Average & $47(14)$ \\
\hline Low & $3(1)$ \\
\hline Very low & $5(1)$ \\
\hline \multicolumn{2}{|c|}{ GP has enough time for patient $t^{\star}(n=331)$} \\
\hline Always & $157 \cdot(47)$ \\
\hline Mostly & $118(36)$ \\
\hline Sometimes & $35(11)$ \\
\hline Rarely & $15(5)$ \\
\hline Never & $6(2)$ \\
\hline \multicolumn{2}{|c|}{ Stronger commitment by GP desirable $(n=334)$} \\
\hline Yes & $88(26)$ \\
\hline No & $194(58)$ \\
\hline No opinion & $52(16)$ \\
\hline
\end{tabular}

A total of 55 patients expressed some detailed wishesô when asked for further suggestions: five wanted more home visits, three wanted methadone to be availableㅡㅁ from the general practitioner, one said his generaf practitioner should acquire better knowledge instead of moralising, and another patient observed that his they were highly satisfied with him or her $(84 \% ; 280) \frac{3}{3}$ 
doctor often looked exhausted and recommended that he work less hard.

\section{Discussion}

We interviewed a large sample of HIV infected patients in two German cities with a relatively high prevalence of this infection. Although our data are not representative of the whole country and no corroboration of the patients' statements was possible, we think that the results of this survey give a good picture of the use and image of primary care physicians among affected patients.

That at least as many HIV patients as members of the general population were registered with a general practitioner is somewhat surprising as in Germany patients with a special chronic illness can easily obtain care exclusively from hospital specialists without parallel registration with a general practitioner. Whether this high rate of acceptance of general practitioners' services is associated with the presumably low social status of these patients (very few had high school education or a university degree) remains speculative.

With respect to sex and risk groups our sample was similar to AIDS patients in a national registry. Because laboratory data on HIV infection (which do not consider disease classification) of ten omit demographic details we did not use these for comparison with our data. Because we identified our population from hospital or clinic attendance we cannot exclude the bias that the patients were more seriously affected by their HIV disease; however, only a fifth of the patients were hospitalised. The less severe disease stage seen in the women compared with the men may be due to a time lag for the infection to occur in women during the course of the epidemic. ${ }^{9}$

As to the place of HIV testing, the slight preference for clinics or hospitals over the general practice surgery does not necessarily mean a preference for one health care institution over the other: testing for sophisticated differential diagnosis occurs more often in the hospital than in general practice. The low rating for public health departments (where HIV antibody assays are done anonymously and free of charge) might indicate that patients did not consider their records to be safe and confidential there. Furthermore, these institutions do not offer routine testing for other diseases or medical care, which might influence patients' decisions.

Why patients (except homosexual or bisexual men) trusted clinics or hospitals more than general practitioners is not readily explained. Problems with intravenous drug users in general practice and the fact that haemophilic patients and perinatally infected children are still rarely cared for by general practitioners could have influenced some patients' preference for clinics. ${ }^{10}$

Most general practitioners were aware of the patient's HIV diagnosis. Some of the few patients who did not inform their general practitioner said that "coming from a small town" was the reason for this reluctance; they apparently had chosen a general practitioner in the bigger city and outside of their home town. We cannot explain the remarkable differences between our results ( $91 \%$ of general practitioners were aware of patients' HIV status) and the data of King's study in London, where many patients were concerned about confidentiality and only $53 \%$ of general practitioners were informed of this diagnosis.
The lack of a significant correlation between patients' statement that they did not routinely inform other doctors (or medical staff) of their HIV status and their ever having been rejected by a doctor or dentist was somewhat surprising as this behaviour might be a reaction towards this attitude of some professionals. It is noteworthy that more patients were denied treatment by dentists than by doctors $-12 \%$ of our patients had been refused treatment by a dentist. Refusal of treatment is problematic from an ethical standpoint, and doctors have been reminded of their duty of care. ${ }^{11}$

The rating of general practitioners' knowledge of HIV as excellent or good by more than two thirds of the patients apparently refers to the ability of general practitioners - and less so of hospital doctors - to help for physical problems only. Otherwise it is difficult to explain why less than a quarter of patients consult a medical professional about psychological problems. This perceived lack of counselling competence has also been reported in a British study. ${ }^{12}$ It is noteworthy, however, that general practitioners did better than their hospital colleagues when confronted with physical or psychological problems.

Because we did not ask for the assumed sexual preference of the general practitioner we do not know if there is an association between the patient's attitude and the doctor's homosexuality. ${ }^{13}$

Most patients expressed a surprisingly high degree of satisfaction with their general practitioners in terms of confidential issues, attitudes, knowledge, and management. Although some problems remain to be solved, many HIV infected people think that they are in good hands with their family doctors. This should challenge and encourage general practitioners to take even more responsibility and commitment with respect to HIV infection and AIDS

We are indebted to Elke Fahrenheim, Engelbert Schroll, and Dr Uwe Wintergerst for help in conducting the interviews.

Part of this work was presented in abstract form at the fifth international conference on AIDS, Montreal, 4-9 June 1989 and at the annual meeting of the German Society of General Practice, Göttingen, 21-25 July 1989.

1 Working party of the Royal College of General Practitioners. Human mmunodeficiency virus infection and the acquired immune deficiency syndrome in general practice. $\mathcal{F} R$ Coll Gen Pract 1988;38:219-25.

2 Bucknall A. Regional patterns of AIDS and HIV infection. $\mathcal{F} R$ Coll Gen Prac 1986;36:491-2

3 Northfelt DW, Hayward RA, Shapiro MF. The acquired immunodeficiency syndrome is a primary care disease. Ann Intern Med 1988;108:773-5.

4 Hodgkin P. HIV infection: the challenge to general practitioners. $B M 7$ 1988;296:516-7.

5 King MB. Psychological and social problems in HIV infection: interviews with general practitioners in London. BMF 1989;299:713-7.

6 Common practions know knowledge and behaviour of general practitioners in relation to HIV
infection and AIDS. Med f A Ast 1990;153:5-12.

King MB. AIDS and the general practitioner: views of patients with HIV infection and AIDS. BMF 1988;297:182-4.

8 Federal Bureau of Statistics. Statistical yearbook of the Federal Republic of Germany. Stuttgart: Metzler-Pöschel, 1990:355.

9 Wofsy CB. Human immunodeficiency virus infection in women. $\mathcal{F}_{A M}$ 1987;257:2074-6.

10 Gallagher M. AIDS and HIV infection: ethical problems for general practitioners. I R Coll Gen Pract 1988;38:414-7.

11 Gillon R. Refusal to treat AIDS and HIV positive patients. BMf 1987;294: 1332-3.

12 Sibbald B, Frieling P. AIDS and the future general practitioner. $f$ R Coll Gen Pract 1988:38:500-2.

13 Bhugra D, King $M$. Controlled comparison of attitudes of psychiatrists, general practitioners, homosexual doctors and homosexual men to male homosexuality. $7 R$ Soc Med 1989;82:603-5.

(Accepted 30 Julv 1991). 